\title{
Desenvolvimento de porta-enxerto de videira em consórcio com plantas de cobertura do solo
}

\section{Development of vine rootstock in intercropped with soil cover crops}

\author{
Gustavo Reis Silva dos Santos Queiroz ${ }^{1}$ (ORCID 0000-0003-4782-7331), Eduardo Pradi Vendruscolo ${ }^{1 *(O R C I D ~ 0000-}$ \\ 0002-3404-8534), Cássio de Castro Seron' (ORCID 0000-0003-4289-931X), Murilo Battistuzzi Martins ${ }^{1}$ (ORCID 0000-0002-8759- \\ 0917), Luiz Fernandes Cardoso Campos² (ORCID 0000-0001-5171-5194), Gabriel Furlan Polo1 (ORCID 0000-0003-0538-8051), \\ Tiago Zoz' (ORCID 0000-0003-2991-5485)
}

${ }^{1}$ Universidade Estadual de Mato Grosso do Sul, Dourados, MS, Brasil. *Autor para correspondência: *agrovendruscolo@gmail.com

${ }^{2}$ Universidade Federal de Goiás, Goiânia, GO, Brasil.

Submissão: 02/02/2021 | Aceite: 16/08/2021

\begin{abstract}
RESUMO
A utilização de plantas de cobertura do solo, no cultivo da videira é uma técnica importante, principalmente para regiões de clima tropical devido às elevadas temperaturas do ar e do solo. Objetivouse com este trabalho avaliar o desenvolvimento do cultivar de porta-enxerto de videira IAC 572 'Jales', consorciado com diferentes plantas de cobertura do solo. O experimento foi conduzido em área experimental da Universidade Estadual do Mato Grosso do Sul - Unidade Universitária de Cassilândia. O delineamento experimental foi em blocos ao acaso, com cinco repetições de duas plantas do portaenxerto, totalizando dez plantas úteis por tratamento. Os tratamentos foram definidos pelas plantas de cobertura: milheto (Pennisetum glaucum); crotolária (Crotalaria juncea); e mamona (Ricinus communis). Foram avaliadas a altura das plantas, diâmetro de caule, número de ramos e teor relativo de clorofila. $\mathrm{O}$ desenvolvimento de porta-enxerto IAC 572 'Jales', é favorecido pelo cultivo consorciado com crotalária e milheto na entrelinha de plantio, pois contribui para maior altura de plantas e maior teor relativo de clorofila. A utilização da cultura da mamona, em consórcio com o porta-enxerto, deve ser evitada. Tais resultados demonstram a importância de se conhecer a interação entre e espécie cultivada e as plantas de cobertura do solo. Desta forma, outras espécies devem ser avaliadas, para cultivo em consócio com a cultura da videira em regiões tropicais.
\end{abstract}

PALAVRAS-CHAVE: Vitis spp., viticultura tropical, conservação do solo, Cerrado brasileiro.

\section{ABSTRACT}

The use of soil cover crops in the cultivation of the vine is an important technique, especially for tropical climate regions due to high air and soil temperatures. Therefore, this work aimed to evaluate the development of the vine rootstock cultivar 'IAC 572 'Jales', intercropped with different types of soil cover plants in the Brazilian Cerrado. The experiment was conducted in an experimental area at the State University of Mato Grosso do Sul - Cassilândia University Unit. The experimental design performed on randomized blocks and with five replications of two rootstock plants, totaling ten useful plants per treatment. The treatments were defined by cover crops: millet (Pennisetum glaucum); crotalaria (Crotalaria juncea); and castor (Ricinus communis). Plant height, stem diameter, number of branches and relative chlorophyll content were evaluated. The development of IAC 572 'Jales' rootstock is favored by the intercropping with crotalaria and millet between the planting rows, as it contributes to greater plant height and higher relative chlorophyll content. The use of castor bean culture, in consortium with the rootstock, should be avoided. These results demonstrate the importance of knowing the interaction between the cultivated species and the ground cover crops. Thus, other species must be evaluated, for cultivation in association with the culture of the vine in tropical regions.

KEYWORDS: Vitis spp., tropical viticulture, soil conservation, Brazilian Savanna.

O avanço tecnológico no manejo e as pesquisas recentes de novos cultivares adaptados às regiões tropicais e subtropicais do Brasil, tornaram o cultivo de uvas uma atividade bem-sucedida técnica e economicamente viável (REIS \& REIS 2016). A viticultura tropical é típica de regiões onde as temperaturas 
mínimas não são suficientemente baixas para induzir a videira à dormência. A videira cresce continuamente e, com o uso de tecnologia apropriada, é possível a obtenção de duas ou mais colheitas por ano, no mesmo parreiral (CAMARGO et al. 2011). Os principais polos de viticultura tropical no Brasil são o Vale do Submédio São Francisco, o noroeste Paulista e o norte de Minas Gerais (MAIA et al. 2018).

No caso da viticultura tropical, principalmente nas regiões Sudeste e Centro-Oeste não é possível a realização de dois ciclos de produção durante o período de estiagem (CAMARGO 2004), nessas regiões a poda de produção é realizada final do verão, assim, busca se alcançar a maturação dos frutos em época seca, ensolarada e com amplitude térmica diária que acarreta aumento do teor de sólidos solúveis (MOURA et al. 2021). Posteriormente à colheita é feita uma poda curta, apenas para formação de varas, com a retirada dos cachos que surgirem. Caracterizando a viticultura com dois ciclos, sendo duas podas e uma colheita por ano (técnica da dupla poda) (ALMANÇA et al. 2020). Produtores dos estados da região Sudeste e Centro-Oeste têm mostrado interesse pelo cultivo de uvas para vinhos finos, em função de localizarem-se próximo aos maiores mercados consumidores do país, e em virtude, também, de condições climáticas especiais, visando aos bons parâmetros de cultivo (MOURA et al. 2021).

Assim como para os cultivares copa, há elevada importância quanto à adaptação de cultivares porta-enxertos, devido à complexidade existente entre os fatores edáficos, desenvolvimento vegetativo, produtividade e qualidade de frutos. Desta maneira, a adaptação do porta-enxerto à uma determinada condição edafoclimática poderá resultar em melhores condições produtivas do parreiral (CAMPOS et al. 2020), da mesma forma que o manejo adequado do ambiente de cultivo, suprirá as demandas das plantas, possibilitando a expressão do seu máximo potencial genético. Nas regiões tropicais, os portaenxertos IAC 313 'Tropical', IAC 572 'Jales' e IAC 766 'Campinas' são os mais difundidos. A partir da década de 1990, entretanto, a maioria dos novos vinhedos, em todas as áreas tropicais do Brasil, foi implantada com o IAC 572 'Jales' (CAMARGO et al. 2011).

Entre as diversas formas de manejo adotadas pela viticultura, a cobertura do solo tem sido aplicada por proporcionar vantagens, tais como a amenização da erosão física e química do solo, redução da incidência de plantas invasoras, aumento da atividade microbiológica e servir como refúgio aos inimigos naturais (NOVARA et al. 2011, SOMMAGGIO et al. 2018, VUKICEVICH et al. 2018). Além destes benefícios, a roçada da parte aérea das plantas de cobertura anuais ou perenes localizadas na linha de plantio, pode ser uma alternativa visando aumentar a disponibilidade de nutrientes à videira através do processo de decomposição e mineralização do material orgânico disposto sobre o solo (BRUNETTO et al. 2011, CAMPOS et al. 2017).

Em avaliação de seis grupos de plantas de cobertura na região do Mediterrâneo, NOVARA et al. (2011) analisaram que um sistema de manejo do solo baseado no plantio de culturas de cobertura entre as fileiras de um vinhedo, retém água e diminui a erosão do solo efetivamente. Segundo MUSCAS et al. (2017), espécies de gramíneas utilizadas como cobertura do solo nas entrelinhas de parreiral, podem melhorar as características produtivas e qualitativas dos frutos de videira, limitando o desenvolvimento vegetativo excessivo. Em seu trabalho com a videira Merlot, conduzida com e sem cobertura vegetal na linha de cultivo, WURZ et al. (2018) observaram que o solo sem cobertura vegetal, resultou em uma melhor maturação da uva, pois houve incremento da relação casca/baga, pH e antocianinas. Avaliando plantas espontâneas na entre linha de videira DAANE et al. (2018) verificaram que essas plantas contribuíram para a redução da cigarrinha dos vinhedos, fornecendo recursos alimentares e ou habitat para os inimigos naturais, além de favorecer a manutenção da umidade do solo, sendo uma técnica importante para culturas perenes em regiões de clima seco. Segundo RICHARDS et al. (2020) as plantas de cobertura, também podem servir como uma linha de defesa contra patógenos fúngicos do solo, produzindo exsudatos radiculares voláteis e ou abrigando microrganismos benéficos.

O consórcio de plantas de cobertura é uma importante ferramenta para o produtor, entretanto, são escassos na literatura trabalhos relacionados ao comportamento dessas plantas em sistemas de cultivo da videira, em região tropical (CAMPOS et al. 2015). Este trabalho considera a hipótese de que diferentes espécies utilizadas como plantas de cobertura na entrelinha podem influenciar o desenvolvimento da videira. Assim, objetivou-se com este trabalho avaliar o desenvolvimento do cultivar de porta-enxerto de videira IAC 572 'Jales', consorciado com diferentes de plantas de cobertura do solo.

O experimento foi conduzido a campo, na Estação Experimental Agrícola da Universidade Estadual do Mato Grosso do Sul - Unidade Universitária de Cassilândia (UEMS/UUC), localizada na latitude de $19^{\circ} 05^{\prime} 30^{\prime \prime}$ S e longitude de $51^{\circ} 05^{\prime} 55^{\prime \prime} \mathrm{W}$, com altitude média de $549 \mathrm{~m}$. O solo presente na área foi

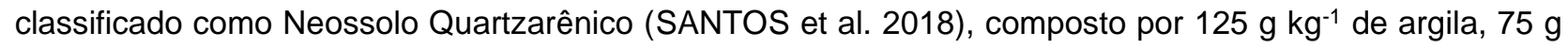
$\mathrm{kg}^{-1}$ de silte e $800 \mathrm{~g} \mathrm{~kg}^{-1}$ de areia, contendo as seguintes características químicas: $\mathrm{pH}\left(\mathrm{CaCl}_{2}\right) 4,4 ; 15 \mathrm{~g} \mathrm{dm}^{-}$ 
${ }^{3}$ de MO; 3,0 mg dm${ }^{-3}$ de Presina; 31,0 $\mathrm{mmol}_{\mathrm{c}} \mathrm{dm}^{-3}$ de $\mathrm{H}+\mathrm{Al} ; 2,9 \mathrm{mmolc}_{\mathrm{dm}}{ }^{-3}$ de $\mathrm{K} ; 11,0 \mathrm{mmolc}_{\mathrm{dm}}{ }^{-3}$ de Ca; $11,0 \mathrm{mmol}_{\mathrm{c}} \mathrm{dm}^{-3}$ de $\mathrm{Mg}$; soma de bases de 25,0 $\mathrm{mmol}_{\mathrm{c}} \mathrm{dm}^{-3}$; capacidade de troca de cátions de $56 \mathrm{mmol}_{\mathrm{c}}$ $\mathrm{dm}^{-3}$ e saturação de bases de $45 \%$.

A área experimental $(9 \times 26 \mathrm{~m})$, foi preparada de maneira convencional, com a utilização da grade aradora, na segunda quinzena de setembro. Após o preparo inicial, procedeu-se a calagem do solo, aplicando-se $2,8 \mathrm{Mg} \mathrm{ha}^{-1}$ de calcário agrícola (70\% de PRNT) em toda a superfície, com incorporação com grade aradora, seguida de grade niveladora, a fim de elevar a saturação por bases à $80 \%$. Posteriormente, a área foi dividida em três parcelas iguais de $78 \mathrm{~m}^{2}$ para o plantio das plantas de cobertura.

O delineamento experimental foi o de blocos ao acaso, com cinco repetições de duas plantas do porta-enxerto, totalizando dez plantas úteis por tratamento. Os tratamentos foram definidos pelas plantas de cobertura: milheto (Pennisetum glaucum); crotolária (Crotalaria juncea); e mamoma (Ricinus communis). Tanto as sementes de milheto quanto as de crotalária foram semeadas a lanço, $25 \mathrm{~kg} \mathrm{ha}^{-1} \mathrm{e}$ $20 \mathrm{~kg} \mathrm{ha}^{-1}$, respectivamente. Para a mamona, a semeadura foi feita em sulcos com cerca de $5 \mathrm{~cm}$ de profundidade, com espaçamento de $50 \mathrm{~cm}$ entre linhas e dez plantas por metro. Todas as sementes foram obtidas de empresas especializadas na produção e comercialização destas.

Aos trinta dias após semeadura das plantas de cobertura, iniciou-se o preparo das covas, com dimensões de $30 \times 30 \times 30 \mathrm{~cm}$, para receber as mudas do porta-enxerto de videira IAC 572 'Jales'. No preparo das covas foram misturados, no solo, $5 \mathrm{~L}$ de esterco bovino curtido e $250 \mathrm{~g}$ de superfosfato simples. As mudas de videira foram formadas a partir de estacas enraizadas em tubetes de $0,5 \mathrm{~L}$, preenchidos com substrato formado por solo, esterco bovino curtido e vermiculita (2:1:1). As estacas permaneceram em estufa com nebulização por dois meses e, após brotadas, as mudas foram transferidas para a aclimatação em telado com $30 \%$ de sombreamento, por 15 dias e posteriormente para sol pleno, por mais 15 dias. As mudas foram plantadas no local definitivo, no dia 13 de dezembro de 2020, no espaçamento de $2 \mathrm{~m}$ entre plantas e $3 \mathrm{~m}$ entre linhas (MAIA et al. 2012). As videiras foram conduzidas em crescimento em espaldeiras, utilizando-se de estacas de bambu e amarrações com barbante.

Aos 50 dias após a semeadura das coberturas vegetais foi realizada a roçagem, visando a redução do seu tamanho e a formação da cobertura sobre o solo. Nesse momento, o milheto estava em floração, enquanto a crotalária e a mamona estavam em crescimento vegetativo.

Aos 60 dias após o plantio do porta enxerto, foram realizadas as seguintes avaliações: altura das plantas, utilizando-se de uma régua graduada e fazendo a mensuração da base até o ápice do ramo principal; diâmetro de caule, medindo-se a porção central do primeiro entrenó do ramo principal com paquímetro digital; número de folhas do ramo principal e número de ramos, contados manualmente; e teor relativo de clorofila, mensurado com um clorofilômetro digital (CCM-200, Opti-Sciences, Hudson, EUA), em folha pertencente ao terço médio da planta, sendo as avaliações realizadas sempre em intervalos de trinta dias, durante o período de três meses. Os dados foram submetidos à análise de variância e as médias comparadas pelo teste LSD a $5 \%$ de probabilidade. As análises foram realizadas software estatístico SISVAR (FERREIRA 2014).

Foram verificadas diferenças significativas em altura de planta e teor relativo de clorofila nos três meses de avaliação e para número de ramos laterais apenas no terceiro mês de avaliação, com superioridade dos tratamentos compostos por milheto e crotalária (Tabela 1). Para as demais variáveis, nos três meses de avaliação, constatou-se a superioridade da crotalária sobre a mamona, porém sem que houvesse diferença significativa para o tratamento com milheto (Tabela 1).

Segundo OLIVEIRA et al. (2007) as plantas de cobertura do solo devem ser manejadas de forma adequada para se evitar competições com as videiras, sendo, os períodos mais críticos de consórcio entre as espécies durante a brotação na primavera e após a colheita da uva quando ocorrem formação e estoque de reservas para o próximo ciclo.

A cobertura com palhada de alta relação $\mathrm{C} / \mathrm{N}$, como do milheto, permite um maior tempo de permanência deste resíduo sobre o solo, proporcionando que ocorra um efeito "guarda-chuva". Esse efeito diminui a força com que a água da chuva atinge a superfície do solo, mantendo a estabilidade das partículas e impedindo que estas sejam carregadas pelo escoamento superficial, mantendo também a qualidade química deste solo, evitando a perda de nutrientes por lixiviação (NOVARA et al. 2018; VENDRUSCOLO et al. 2018).

Considerando as condições de clima tropical bem definido por inverno quente e seco e verão quente e chuvoso, o processo de decomposição da matéria orgânica provida de coberturas verde é acelerado (PACHECO et al. 2011). Principalmente quando as plantas são cortadas em estágios vegetativos, sendo que plantas mais novas são mais rapidamente decompostas em condições de clima quente (CAMPOS et 
al. 2015). Devido a isso, as características mais importantes nas plantas de cobertura são a quantidade e a durabilidade da fitomassa produzida (BOER et al. 2008, LEITE et al. 2010), bem como a sua capacidade de ciclagem de nutrientes.

Tabela 1. Altura de planta (ALT), diâmetro do caule (DC), número de ramos (NR), número de folhas do ramo principal (NFP) e teor relativo de clorofila (TRC) de porta-enxerto IAC 572, em consórcio com diferentes plantas de cobertura do solo.

Table 1. Plant height (ALT), stem diameter (DC), number of branches (NR), number of leaves in the main branch (NFP) and relative chlorophyll content (TRC) of IAC 572 rootstock, in intercropping with different cover crops.

\begin{tabular}{|c|c|c|c|c|c|c|}
\hline Data & Cobertura do solo & $\begin{array}{l}\text { ALT } \\
(\mathrm{cm})\end{array}$ & $\begin{array}{c}\text { DC } \\
(\mathrm{mm})\end{array}$ & $\begin{array}{c}\text { NR } \\
-\end{array}$ & $\begin{array}{c}\text { NFP } \\
-\end{array}$ & $\begin{array}{c}\text { TRC } \\
\text { (SPAD) }\end{array}$ \\
\hline & Milheto & $104,39 a$ & $3,33 a b$ & $6,10 a b$ & $32,80 \mathrm{ab}$ & $15,02 a$ \\
\hline \multirow[t]{2}{*}{$60 \mathrm{DAP}$} & Crotalária & $94,99 a$ & $3,62 a$ & $6,70 \mathrm{a}$ & $36,20 a$ & $13,97 a$ \\
\hline & Mamona & $62,99 \mathrm{~b}$ & $2,84 b$ & $5,10 \mathrm{~b}$ & $28,00 \mathrm{~b}$ & $11,31 \mathrm{~b}$ \\
\hline CV\% & & 24,04 & 16,41 & 25,06 & 26,78 & 18,87 \\
\hline DMS & & 19,45 & 0,50 & 1,38 & 8,01 & 2,35 \\
\hline \multirow{3}{*}{$90 \mathrm{DAP}$} & Milheto & $106,87 a$ & $3,40 a b$ & $7,30 a b$ & $40,10 a b$ & $15,80 \mathrm{a}$ \\
\hline & Crotalária & $97,64 a$ & $3,76 a$ & $8,40 a$ & $48,00 a$ & $14,80 \mathrm{a}$ \\
\hline & Mamona & $66,44 \mathrm{~b}$ & $2,92 b$ & $6,20 \mathrm{~b}$ & $35,00 \mathrm{~b}$ & $12,04 b$ \\
\hline CV\% & & 24,10 & 16,89 & 25,11 & 22,56 & 17,45 \\
\hline DMS & & 20,14 & 0,53 & 1,70 & 8,56 & 2,30 \\
\hline \multirow{3}{*}{$120 \mathrm{DAP}$} & Milheto & $110,34 a$ & $3,43 a b$ & $9,60 a$ & $49,10 a b$ & $15,51 \mathrm{a}$ \\
\hline & Crotalária & $100,55 a$ & $3,82 a$ & $10,60 a$ & $55,20 a$ & $15,37 a$ \\
\hline & Mamona & $69,51 \mathrm{~b}$ & $3,06 \mathrm{~b}$ & $7,40 \mathrm{~b}$ & $44,40 \mathrm{~b}$ & $12,52 b$ \\
\hline CV\% & & 23,81 & 17,97 & 24,49 & 19,98 & 18,14 \\
\hline DMS & & 20,59 & 0,57 & 2,08 & 9,16 & 2,43 \\
\hline
\end{tabular}

Médias seguidas de mesma letra nas colunas não diferem entre si pelo teste LSD a $5 \%$ de probabilidade. DAP = dias após o plantio.

Além dos benefícios supracitados, o crescimento abundante da crotalária, permite uma melhor cobertura do solo, reduzindo o desenvolvimento de plantas espontâneas, o que diminui a competição por recursos. Em complemento, verifica-se que a espécie também realiza uma série de interações com os organismos do solo, permitindo a fixação biológica de nitrogênio, e sua disponibilização após o corte (ÁVILA et al. 2020).

Por sua vez o consórcio da mamona com o porta-enxerto de videira IAC 572 'Jales' proporcionou os menores valores, principalmente nas variáveis altura de planta e teor relativo de clorofila (Tabela 1). Em geral, a produtividade das culturas é reduzida quando cultivada em consórcio com esta espécie. Como observado para o consórcio entre mamoneira com gergelim, algodão, milho, feijão-caupi (PINTO et al. 2011), amendoim (BELTRÃO et al. 2010) e sorgo (CORRÊA et al. 2006), sendo os rendimentos dessas culturas no consórcio é inferior ao obtido em cultivo sem consórcio, com a cultura da mamona. Isso, provavelmente se deve aos compostos presentes nos diferentes órgãos da mamoneira, provenientes do metabolismo secundário, que em elevadas concentrações, interferem negativamente no estabelecimento de outras espécies (RIGON et al. 2013).

Desta maneira, além de se avaliar a produtividade, deve-se observar outros índices que auxiliem na escolha da melhor espécie de planta no consórcio. Quando realizado de maneira correta este consórcio pode agregar vantagens: ambientais, como melhoria e preservação das características do solo; e econômicas, como menor gasto com fertilizantes e herbicidas. Em contrapartida, a utilização de espécies não adequadas, seja pela presença de compostos alelopáticos, por excesso de competição interespecífica ou outras interações deletérias, pode levar ao desenvolvimento inadequado das videiras e resultar em perdas produtivas.

O desenvolvimento do porta-enxerto IAC 572 'Jales', é favorecido pelo cultivo consorciado com crotalária e milheto na entrelinha de plantio, favorecendo principalmente o crescimento de ramo e maior teor relativo de clorofila. O consórcio do porta-enxerto IAC 572 'Jales', com a cultura da mamona deve ser evitado, pois não favorece o seu desenvolvimento. 


\section{REFERÊNCIAS}

ALMANÇA MAK et al. 2020. Controle de doenças e pragas da videira em vinhedos conduzidos em regime de dupla poda. Informe Agropecuário 41: 52-62.

ÁVILA J et al. 2020. Cover crops change the phytosociology of weeds and the banana yield. Journal of Neotropical Agriculture 7: 53-59.

BELTRÃO NEM. et al. 2010. Consórcio mamona e amendoim: opção para a agricultura familiar. Revista Verde de Agroecologia e Desenvolvimento Sustentável 5: 222-227.

BOER CA et al. 2008. Biomassa, decomposição e cobertura do solo ocasionada por resíduos culturais de três espécies vegetais na região Centro Oeste do Brasil. Revista Brasileira de Ciência do Solo 32: 843-851.

BRUNETTO $\mathrm{G}$ et al. 2011. Nutrient release during the decomposition of mowed perennial ryegrass and white clover and its contribution to nitrogen nutrition of grapevine. Nutrient Cycling in Agroecosystems 90: 299-308.

CAMARGO UA et al. 2011. Progressos na viticultura brasileira. Revista Brasileira de Fruticultura 33: 144- 149.

CAMARGO UA. 2004. 'Isabel Precoce': Alternativa para a Vitivinicultura Brasileira. Comunicado Técnico 54. Bento Gonçalves: Embrapa Uva e Vinho.

CAMPOS LFC et al. 2015. Plantas de cobertura do solo em área de videira rústica cultivada no cerrado goiano. Amazonian Journal of Agricultural and Environmental Sciences 58: 184-191.

CAMPOS LFC et al. 2017. Desenvolvimento, produtividade e qualidade dos frutos da videira em consórcio com culturas de cobertura. Revista de Ciências Agroveterinárias 16: 396-405.

CAMPOS LFC et al. 2020. Vegetative development of vine rootstock cultivars in brazilian cerrado conditions. Colloquium Agrariae 16: 121-129.

CORREAA MLP et al. 2006. Comportamento de cultivares de mamona em sistemas de cultivo isolados e consorciados com caupi e sorgo granífero. Revista Ciência Agronômica 37: 200-207.

DAANE KM et al. 2018. Native grass ground covers provide multiple ecosystem services in Californian vineyards. Journal of Applied Ecology 55:2473-2483.

FERREIRA DF. 2014. Sisvar: a Guide for its Bootstrap procedures in multiple comparisons. Ciência e Agrotecnologia 38 : 109-112.

LEITE LFC et al. 2010. Decomposição e liberação de nutrientes de resíduos vegetais depositados sobre Latossolo Amarelo no Cerrado Maranhense. Revista Ciência Agronômica 41: 29-35.

MAIA JDG et al. 2012. O cultivo da videira Niágara no Brasil. Brasília: Embrapa.

MAIA JDG et al. 2018. A Viticultura de Mesa no Brasil, Territoires du vin, 9. Disponível em: http://preo.ubourgogne.fr/territoiresduvin/index.php?id=1546. Acesso em: 09 ago 2021.

MOURA MF et al. 2021. Uvas de interesse econômico para vinificação e consumo in natura. Revista Visão Agrícola 14: 8-13.

MUSCAS E et al. 2017. Effects of vineyard floor cover crops on grapevine vigor, yield, and fruit quality, and the development of the vine mealybug under a Mediterranean climate. Agriculture, Ecosystems \& Environment 237: 203212.

NOVARA A et al. 2011. Soil erosion assessment on tillage and alternative soil management Sicilian vineyard. Soil \& Tillage Research 117:140-147.

NOVARA A et al. 2018. Sustainable vineyard floor management: an equilibrium between water consumption and soil conservation. Current Opinion in Environmental Science \& Health 5: 33-37.

OLIVEIRA OLP et al. 2007. Manejo da cobertura do solo em videiras visando à sustentabilidade do ecossistema: relação das espécies de cobertura com as videiras e com a produção e qualidade da uva. Revista Brasileira de Agroecologia 2: 1198-1201.

PACHECO LP et al. 2011. Produção de fitomassa e acúmulo e liberação de nutrientes por plantas de cobertura na safrinha. Pesquisa Agropecuária Brasileira 46: 17-25.

PINTO CM et al. 2011. Produtividade e índices competição da mamona consorciada com gergelim, algodão, milho e feijão caupi. Revista Verde 6: 75-85.

REIS L \& REIS PC. 2016. Viabilidade econômica do cultivo de uva irrigada no município de Petrolina, PE. Enciclopédia Biosfera 13: 1089-1099.

RICHARDS A et al. 2020. Cover crop diversity as a tool to mitigate vine decline and reduce pathogens in vineyard soils. Diversity 12:128.

RIGON CAG et al. 2013. Potencial alelopático de extratos de mamoneira sobre a germinação e crescimento de azevém. Tecnologia \& Ciência Agropecuária 7: 1-7.

SANTOS HG et al. 2018. Sistema brasileiro de classificação de solos. 5.ed. Brasília: Embrapa.

SOMMAGGIO D et al. 2018. The effect of cover plants management on soil invertebrate fauna in vineyard in Northern Italy. BioControl 63: 795-806.

VENDRUSCOLO EP et al. 2018. Effect of cover crops residues on crambe cultivation. Revista Facultad Nacional de Agronomía Medellín 71: 8517-8523.

VUKICEVICH E et al. 2018. Groundcover management changes grapevine root fungal communities and plant-soil feedback. Plant and Soil 424: 419-433.

WURZ DA et al. 2018. Efeito do manejo da cobertura do solo na maturação da videira Merlot cultivada em região de elevada altitude. Revista Eletrônica Científica da UERGS 4:152-158. 